\title{
Gender-related disparities in the treatment and outcomes in patients with non-ST-segment elevation myocardial infarction: results from the Polish Registry of Acute Coronary Syndromes (PL-ACS) in the years 2012-2014
}

\author{
Łukasz Piątek ${ }^{1,2}$, Krzysztof Wilczek ${ }^{3}$, Jacek Kurzawski², Marek Gierlotka4 ${ }^{4}$, Mariusz Gąsior ${ }^{3}$, \\ Lech Poloński ${ }^{3}$, Marcin Sadowski ${ }^{1,5}$
}

\author{
${ }^{1}$ The Faculty of Medicine and Health Sciences, Jan Kochanowski University, \\ Department of Anatomy, Kielce, Poland \\ ${ }^{2} 2^{\text {nd }}$ Department of Cardiology, Świętokrzyskie Cardiology Centre, Kielce, Poland \\ ${ }^{3} 3^{\text {rd }}$ Department of Cardiology, School of Medicine with the Division of Dentistry \\ in Zabrze, Medical University of Silesia in Katowice, Silesian Centre for Heart \\ Disease, Zabrze, Poland \\ ${ }^{4}$ Department of Cardiology, University Hospital, Institute of Medicine, University of Opole, \\ Poland \\ ${ }^{5}$ Catheterisation Laboratory, Świętokrzyskie Cardiology Centre, Kielce, Poland
}

Submitted: 3 November 2017

Accepted: 14 January 2018

Arch Med Sci 2020; 16 (4): 781-788

DOI: https://doi.org/10.5114/aoms.2018.76112

Copyright (c) 2020 Termedia \& Banach

\begin{abstract}
Introduction: Gender-related differences in the treatment of patients with non-ST elevation myocardial infarction (NSTEMI) have been reported in many previous studies despite the fact that an equal approach is recommended in all current guidelines. The aim of the study was to investigate whether gender-related discrepancies in the management of NSTEMI patients have changed.

Material and methods: Between 2012 and 2014 a total of 66,667 patients (38.3\% of whom were women) with the final diagnosis of NSTEMI were included into the retrospective analysis of the Polish Registry of Acute Coronary Syndromes (PL-ACS). Differences in clinical profile, treatment, and outcomes were analysed.

Results: Women were older than men and more often had comorbidities. They were less likely to undergo coronary angiography $(88.4 \%$ vs. $92.1 \%$, $p<0.05)$ as well as percutaneous coronary intervention $(59.6 \%$ vs. $71.9 \%$, $p<0.05)$. In the general population women had also significantly worse in-hospital prognosis as well as in 12-month follow-up. After the age adjustment the outcomes in women were at least as good as in men. In multivariate analysis females had the same risk as men in-hospital $R R=1.02$ (95\% Cl: $0.97-1.08, p=0.45)$ and lower in 12-month observation $\mathrm{RR}=0.94$ (95\% Cl: 0.92-0.97, $p<0.0001$ ).

Conclusions: In comparison with previous reports on NSTEMI patients, gender-related disparities in the treatment and outcomes were radically reduced. Unadjusted mortality rates were still higher in women as a consequence of their older age. After the age adjustment, mortality ratios were similar in both genders. The long-term prognosis seems to be even better in women.
\end{abstract}

Key words: women, elderly, mortality, non-ST elevation myocardial infarction, invasive treatment.

\author{
Corresponding author: \\ Łukasz Piątek MD \\ $2^{\text {nd }}$ Department of Cardiology \\ Świętokrzyskie Cardiology \\ Centre \\ 45 Grunwaldzka St \\ 25-736 Kielce, Poland \\ E-mail: piatas22@op.pl
}




\section{Introduction}

In many previous studies on non-ST-segment elevation myocardial infarction (NSTEMI) patients, gender-related differences in the management and outcomes have been reported. Despite the fact that the guidelines recommend the same therapy for both men and women, significant disparities between genders are still observed in many countries. The differences are particularly notable in acute coronary syndromes without ST-segment elevation due to a variable clinical manifestation as well as different comorbidities. Older patients and women are often excluded from the clinical trials, and thus the results of prior reports were sometimes contradictory. The final impact of sex category on prognosis remains unclear. We sought to investigate whether the gender-related differences in the management and prognosis in NSTEMI patients still persist.

\section{Material and methods}

We conducted a retrospective cohort study analysis of the Polish Registry of Acute Coronary Syndromes (PL-ACS). The basic principles of our registry have been published elsewhere [1, 2]. Briefly, a total of 463 hospitals providing care for patients with myocardial infarction contributed to the registry. This analysis covers 3 years, from 2012 to 2014. Data on 66,667 patients were collected in that period. Contribution to the study was voluntary; nevertheless, it comprises more than a half of all NSTEMI cases in Poland in that time. The inclusion criterion was a diagnosis of NSTEMI as a basic clinical condition according to the guidelines of European Society of Cardiology released in 2011. Cases with myocardial ischaemia secondary to other critical conditions were excluded. The study complies with the Declaration of Helsinki and was approved by the PL-ACS Registry committee.

Data were collected from the PL-ACS Registry questionnaires that include variables on demographic factors (gender, age), risk factors (smoking, hyper-

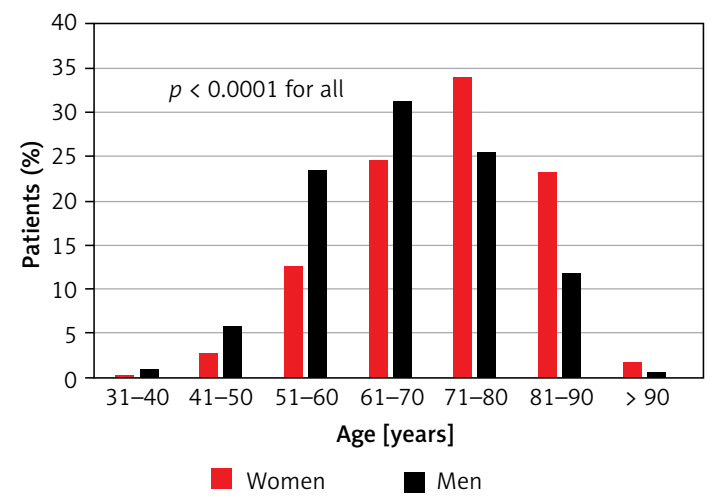

Figure 1. Age histogram of patients with non-ST elevation myocardial infarction in 2012-2014 tension, hypercholesterolaemia, diabetes, and obesity), previous cardiovascular history and procedures (myocardial infarction - Ml, percutaneous coronary intervention - $\mathrm{PCl}$, coronary artery by-pass grafting - CABG), clinical presentation on admission (Killip class, heart rate, systolic blood pressure, electrocardiographic abnormalities, left ventricular ejection fraction in echocardiography ejection fraction (EF)), in-hospital management (coronary angiography, percutaneous coronary intervention, medical treatment), and medication on discharge. In-hospital, 30-day, 6-month, and 12-month follow-up mortality rates were estimated. Kaplan-Meier survival curves and the log-rank test were used to compare the survival between groups.

\section{Statistical analysis}

The gender groups were analysed separately and afterward compared to each other. To investigate the age impact on outcomes additional analyses were conducted in age groups (below 55 , between 55 and 64, between 65 and 74, and over 75 years) as well as in consecutive decades of life.

Categorical data are summarised as frequency and percentage while continuous data as median or arithmetic mean \pm standard deviation (SD). Differences in categorical variables were tested by $\chi^{2}$ test with Pearson modification whereas in continuous variables with Student's $t$-test. A two-sided $p$-value $\leq 0.05$ was considered significant. A logistic regression was used to identify variables that independently contributed to mortality. The relative risk (RR) and 95\% confidence intervals (CI) were calculated.

\section{Results}

Women constituted 25,542 (38.3\%) of the study population. They were older than men, and they predominated in the over 70 age group (Figures 1 and 2). They more often had a history of arterial hypertension, diabetes, and obesity. On the contrary, they less often were smokers and had histo-

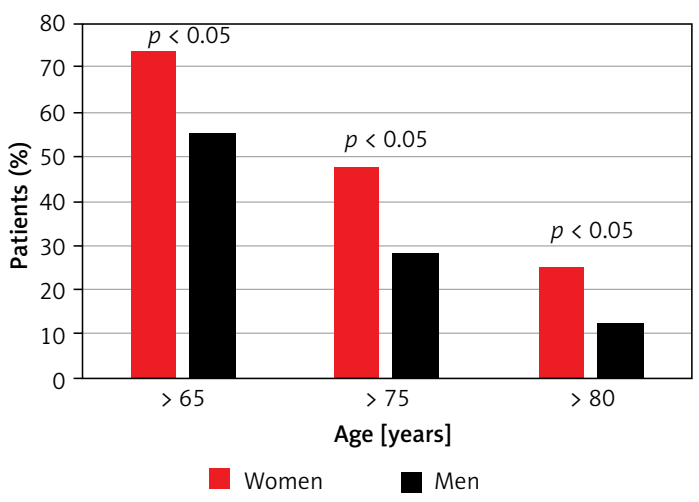

Figure 2. The elderly contribution in patients with non-ST elevation myocardial infarction in 2012-2014 
ry of prior myocardial infarction or revascularisation therapy either by $\mathrm{PCI}$ or CABG (Table I).

Mild gender disparities in medical therapy were observed. Men more often were administered aspirin, clopidogrel, and statin while women received more calcium channel blockers (CCB). There were no differences in administration of $\beta$-blockers, angiotensin-converting enzyme inhibitors (ACEI), angiotensin II receptor blockers (ARB), and nitrates (Table II).

Women less frequently underwent coronary angiography (88.4\% vs. $92.1 \%$ in men; $p<0.0001)$ and $\mathrm{PCl}(59.6 \%$ vs. $66.1 \%$ in men; $p<0.0001)$.
The ratio of patients managed invasively to those treated medically was age-dependent and was the lowest in patients over 75 years old. Interestingly, the differences in $\mathrm{PCl}$ utilisation were especially noticeable among patients under 55 years old ( $59.6 \%$ vs. $71.9 \%$ in men; $p<0.0001)$ (Table III). In women the risk of stroke $(0.3 \%$ vs. $0.2 \%$ in men; $p<0.05)$, bleeding complications (1.5\% vs. $1.0 \%$ in men; $p<0.05)$, as well as cardiovascular death (3.1\% vs. $2.3 \%$ in men; $p<0.05)$ was higher than in men.

The unadjusted in-hospital and 12-month mortality rates remained far higher in women - in

Table I. Clinical characteristics of patients with non-ST elevation myocardial infarction in 2012-2014

\begin{tabular}{|lccc|}
\hline Factor & $\begin{array}{c}\text { Women } \\
n(\%)\end{array}$ & $\begin{array}{c}\text { Men } \\
n(\%)\end{array}$ & $P$-value \\
\hline Hypertension & $20,568(80.5)$ & $31,219(75.9)$ & $<0.05$ \\
\hline Diabetes & $9623(37.3)$ & $11,999(29.2)$ & $<0.05$ \\
\hline Hypercholesterolaemia & $11,262(44.1)$ & $18,067(43.9)$ & 0.67 \\
\hline Smoking & $3340(13.1)$ & $10,989(26.7)$ & $<0.05$ \\
\hline Obesity & $6391(25.0)$ & $7807(19.0)$ & $<0.05$ \\
\hline Previous MI & $5681(22.2)$ & $10,728(26.1)$ & $<0.05$ \\
\hline Previous PCI & $4301(16.8)$ & $8534(20.8)$ & $<0.05$ \\
\hline Previous CABG & $1092(4.3)$ & $2755(6.7)$ & $<0.05$ \\
\hline
\end{tabular}

MI - myocardial infarction, $P C I$ - percutaneous coronary intervention, CABG - coronary artery by-pass grafting.

Table II. Medication on discharge

\begin{tabular}{|c|c|c|c|}
\hline Factor & $\begin{array}{c}\text { Women } \\
n(\%)\end{array}$ & $\begin{array}{c}\text { Men } \\
n(\%)\end{array}$ & $P$-value \\
\hline Aspirin & $21,898(88.7)$ & $35,904(89.5)$ & $<0.05$ \\
\hline Clopidogrel & $18,893(76.5)$ & $31,072(77.5)$ & $<0.05$ \\
\hline$\beta$-Blocker & $16,593(76.6)$ & $24,079(76.4)$ & 0.42 \\
\hline ACEI/ARB & $18,779(76.1)$ & $30,767(76.7)$ & 0.05 \\
\hline Statin & $17,340(85.0)$ & $25,702(85.6)$ & $<0.05$ \\
\hline Nitrate & 2577 (10.4) & 4151 (10.4) & 0.73 \\
\hline CCB & 3675 (14.9) & $5112(12.7)$ & $<0.05$ \\
\hline
\end{tabular}

$A C E I$ - angiotensin-converting enzyme inhibitors, $A R B$ - angiotensin receptor blockers, $C C B$ - calcium channel blockers.

Table III. Invasive treatment

\begin{tabular}{|c|c|c|c|c|c|c|}
\hline \multirow[t]{2}{*}{ Age groups } & \multicolumn{3}{|c|}{ Coronary angiography } & \multicolumn{3}{|c|}{ Percutaneous coronary intervention } \\
\hline & $\begin{array}{c}\text { Women } \\
n(\%)\end{array}$ & $\begin{array}{c}\text { Men } \\
n(\%)\end{array}$ & $P$-value & $\begin{array}{c}\text { Women } \\
n(\%)\end{array}$ & $\begin{array}{l}\text { Men } \\
n(\%)\end{array}$ & $P$-value \\
\hline$<55$ years & $1542(93.6)$ & 5195 (95.0) & $<0.05$ & $980(59.5)$ & 3929 (71.9) & $<0.05$ \\
\hline $55-64$ years & 4717 (94.0) & $12189(94.4)$ & 0.38 & $3270(65.2)$ & 8958 (69.3) & $<0.05$ \\
\hline $65-74$ years & 6233 (91.9) & $10366(92.8)$ & $<0.05$ & $4170(61.5)$ & 7305 (65.4) & $<0.05$ \\
\hline$\geq 75$ years & $10097(83.5)$ & $10124(87.5)$ & $<0.05$ & $6808(56.3)$ & $7006(60.5)$ & $<0.05$ \\
\hline
\end{tabular}


the years 2012-2014 the in-hospital mortality rate was $3.3 \%$ in women vs. $2.5 \%$ in men; $p<0.0001$, while the 12 -month mortality rate was $15.1 \%$ in women vs. $12.8 \%$ in men: $p<0.0001$, respectively.

When analysing the mortality according to age there were no differences in the in-hospital mortality between genders (Figure 3). Women had even better long-term prognosis. In the seventh, eighth, and ninth decades of life their 12-month mortality rates were lower than in men (Figure 4).

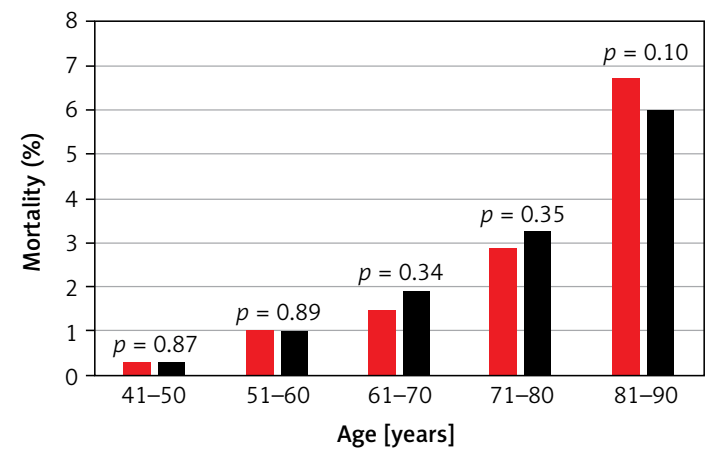

Figure 3. In-hospital mortality rates in consecutive decades of life

A

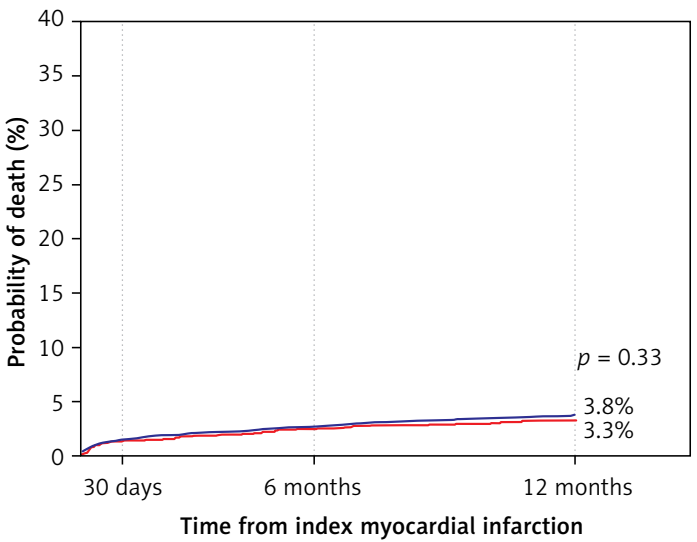

C

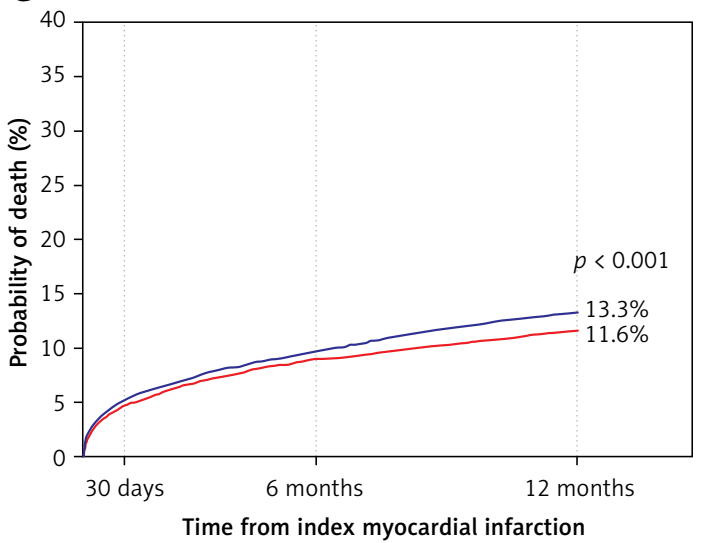

- Men - years 2012-2014
Mortality analysis adjusted to age groups is presented in Figure 5. When analysing only patients who underwent $\mathrm{PCl}$ there were no differences between genders in the short-term prognosis whereas women had lower mortality rates in the age group of 65 to 74 years. Mortality analysis adjusted to strategy of treatment is presented in Figure 6. Multivariable analysis was performed, and there were no differences between gender in in-hospital observation $(\mathrm{RR}=1.02,95 \% \mathrm{Cl}$ : 0.97-1.08,

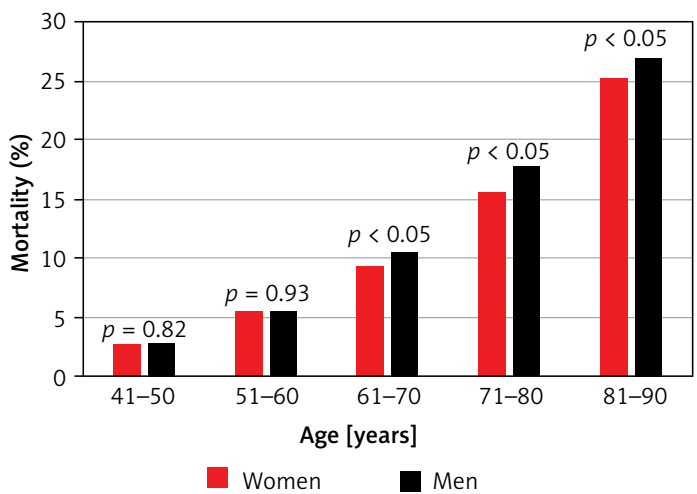

Figure 4. 12-month mortality rates in the consecutive decades of life

B

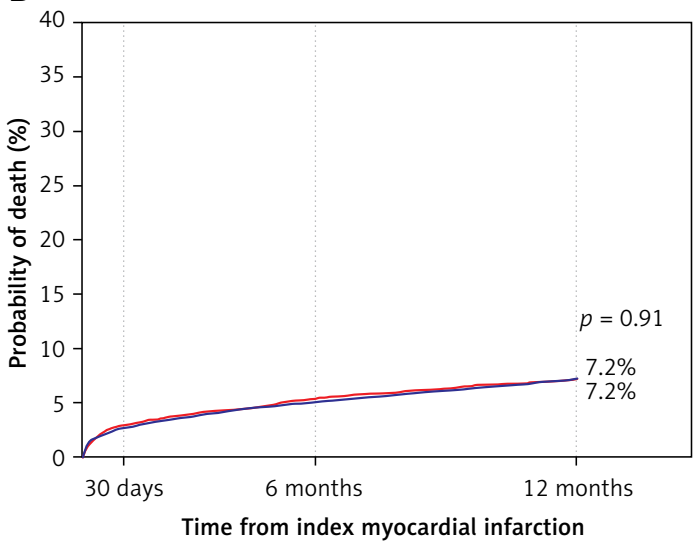

D

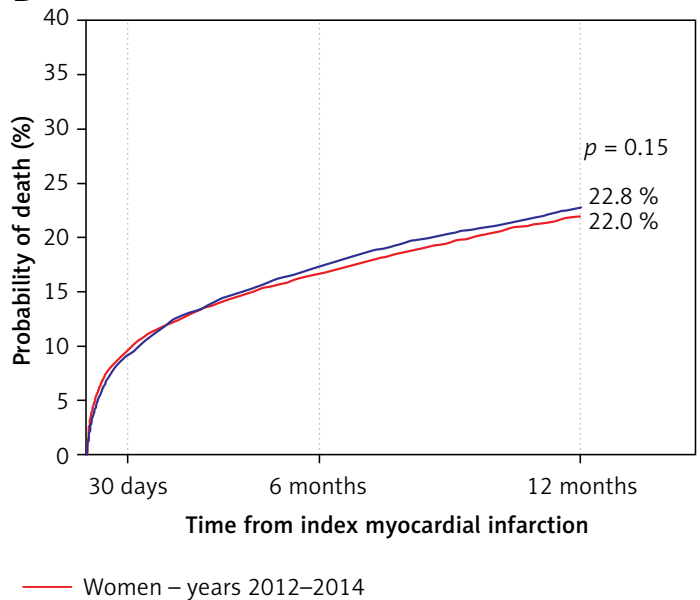

Figure 5. 12-month mortality in age groups: A - age < 55, B - age 55-64, C - age 65-74, D - age $\geq 75$ years 
A

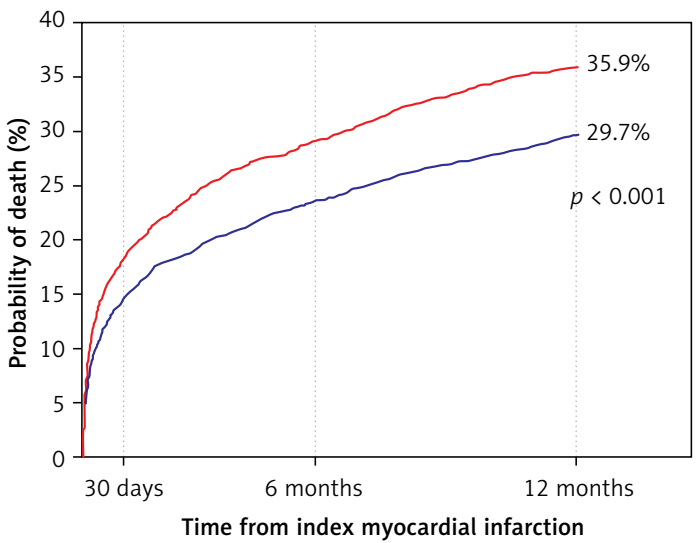

- Men - years 2012-2014
B

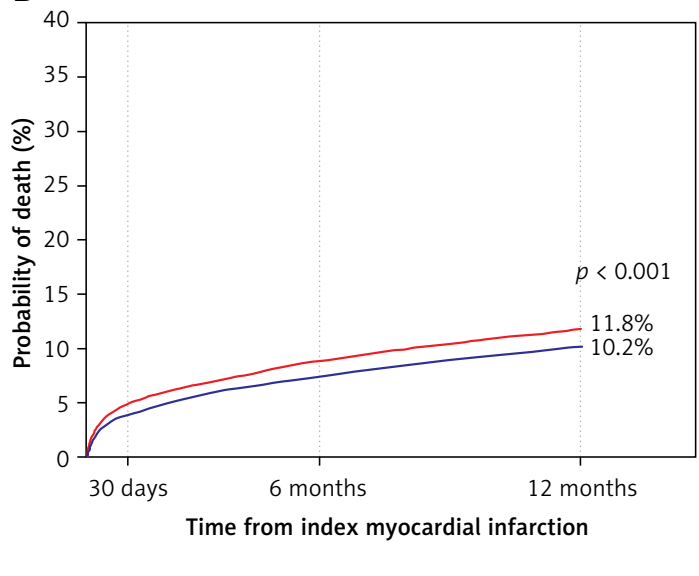

Women - years 2012-2014

Figure 6. 12-month mortality adjusted to strategy of treatment: A - conservative strategy, B - invasive strategy

Table IV. Multivariate analysis of factors influencing in-hospital mortality

\begin{tabular}{|c|c|c|}
\hline Factor & RR $(95 \% \mathrm{Cl})$ & $P$-value \\
\hline Invasive treatment & $0.31(0.29-0.33)$ & $<0.0001$ \\
\hline Hypercholesterolaemia & $0.73(0.69-0.77)$ & $<0.0001$ \\
\hline Hypertension & $0.73(0.69-0.78)$ & $<0.0001$ \\
\hline Previous $\mathrm{PCl}$ & $0.80(0.73-0.88)$ & $<0.0001$ \\
\hline Previous CABG & $0.80(0.71-0.91)$ & 0.0006 \\
\hline Current smokers & $1.02(0.94-1.10)$ & 0.6776 \\
\hline Female (vs. male) & $1.02(0.97-1.08)$ & 0.4485 \\
\hline Previous MI & $1.07(1.01-1.14)$ & 0.0255 \\
\hline Diabetes & $1.09(1.03-1.15)$ & 0.0021 \\
\hline Time to admission $>12 \mathrm{~h}$ & $1.09(1.03-1.16)$ & 0.0030 \\
\hline$E F=35-50 \%$ & $1.10(1.01-1.20)$ & 0.0240 \\
\hline ST-T abnormalities on ECG & $1.16(1.07-1.27)$ & 0.0007 \\
\hline Obesity & $1.18(1.10-1.26)$ & $<0.0001$ \\
\hline Other than sinus rhythm on ECG & $1.19(1.12-1.27)$ & $<0.0001$ \\
\hline Age (on each decade) & $1.63(1.59-1.68)$ & $<0.0001$ \\
\hline$E F<35 \%$ & $2.31(2.11-2.53)$ & $<0.0001$ \\
\hline Prehospital cardiac arrest & $2.37(2.09-2.69)$ & $<0.0001$ \\
\hline Killip 3 class & $3.67(3.41-3.94)$ & $<0.0001$ \\
\hline IABP & $3.89(3.23-4.69)$ & $<0.0001$ \\
\hline Killip 4 class & $13.2(12.0-14.4)$ & $<0.0001$ \\
\hline
\end{tabular}

EF - ejection fraction, ECG - electrocardiogram, IABP - intra aortic balloon pomp. Other abbreviations as in Table I.

$p=0.45$ ) (Table IV). On the other hand, female sex was one of the independent factors that improved 12-month prognosis $(\mathrm{RR}=0.94,95 \% \mathrm{Cl}$ : 0.92-0.97, $p<0.0001$ ) (Table V). These results were in accordance with our previous observa- tion in the age groups. One of the most important variables that has a substantial impact on mortality rates is the age of the patients. With each decade of life the relative risk of death increases rapidly; in short-term prognosis $\mathrm{RR}=1.63(95 \% \mathrm{Cl}$ : 
Table V. Multivariate analysis of factors influencing 12-month mortality

\begin{tabular}{|c|c|c|}
\hline Parameter & OR $(95 \% \mathrm{Cl})$ & $P$-value \\
\hline Invasive treatment & $0.51(0.49-0.52)$ & $<0.0001$ \\
\hline Hypercholesterolaemia & $0.81(0.79-0.83)$ & $<0.0001$ \\
\hline Previous CABG & $0.84(0.80-0.88)$ & $<0.0001$ \\
\hline Hypertension & $0.85(0.83-0.88)$ & $<0.0001$ \\
\hline Previous $\mathrm{PCl}$ & $0.90(0.87-0.94)$ & $<0.0001$ \\
\hline Female (vs. male) & $0.94(0.92-0.97)$ & $<0.0001$ \\
\hline Obesity & $0.99(0.96-1.02)$ & 0.37 \\
\hline Time to admission $>12 \mathrm{~h}$ & $1.03(1.00-1.06)$ & 0.022 \\
\hline Current smokers & $1.06(1.03-1.10)$ & 0.0005 \\
\hline Previous MI & $1.12(1.09-1.15)$ & $<0.0001$ \\
\hline ST-T abnormalities on ECG & $1.15(1.11-1.19)$ & $<0.0001$ \\
\hline Other than sinus rhythm on ECG & $1.14(1.11-1.18)$ & $<0.0001$ \\
\hline Diabetes & $1.29(1.26-1.32)$ & $<0.0001$ \\
\hline$E F=35-50 \%$ & $1.52(1.47-1.57)$ & $<0.0001$ \\
\hline Age (each decade) & $1.57(1.55-1.59)$ & $<0.0001$ \\
\hline Prehospital cardiac arrest & $1.74(1.63-1.85)$ & $<0.0001$ \\
\hline Killip 3 class & $1.98(1.91-2.06)$ & $<0.0001$ \\
\hline IABP & $2.17(1.99-2.38)$ & $<0.0001$ \\
\hline$E F<35 \%$ & $2.67(2.57-2.78)$ & $<0.0001$ \\
\hline Killip 4 class & $4.48(4.26-4.71)$ & $<0.0001$ \\
\hline
\end{tabular}

Abbreviations as in Tables I and IV.

1.59-1.68, $p<0.0001)$, whereas in long-term prog nosis $\mathrm{RR}=1.57(95 \% \mathrm{Cl}: 1.55-1.59, p<0.0001)$.

\section{Discussion}

In many previous studies gender-related disparities in the treatment and outcomes of acute coronary syndromes have been reported. There are concerns that women less frequently receive optimal therapy according to the contemporary guidelines [3]. In particular, invasive procedures have been underutilised in the past [4-9]. In the French Registry FAST-MI 2005 the likelihood of having an invasive strategy was 34\% lower in women compared to men. Five years later, in FAST 2010, the disproportion between genders was less indicated but still observed $(\mathrm{OR}=0.84)$. Additionally, in many studies an adverse prognosis in women was pronounced $[8,10,11]$.

A significant body of evidence indicates that several differences in the demographic and clinical profile among man and women with NSTEMI exist. Women are older and predominate in older groups. Almost half of them are over 75 years old while a quarter are over 80 years old. They more frequently have a history of hypertension, diabetes and renal failure. Moreover, atypical symptoms that delay the diagnosis are more often encountered in women. This implies analyses adjusted for age $[12,13]$.

The majority of former studies have revealed significant inequalities in the application of recommended medical and invasive therapies. In the report by Blomkalns et al. the likelihood of coronary angiography and subsequent invasive treatment in women was up to $30 \%$ lower than in men [7]. In our study the differences were diminished substantially, and in the medical treatment they are just minimal.

A similar trend in the application of invasive procedures has been observed. That means that previously reported gender discrimination in that matter is no longer apparent [14-16]. Similarly, the percutaneous coronary intervention $(\mathrm{PCl})$ rate in women was far greater than was reported in previous studies. However, women still tend to have less $\mathrm{PCl}$ that their male counterparts. We speculate that non-obstructive coronary artery 
disease may partially explain this issue $[3,8]$. In the French Study ONACl women more frequently had nonsignificant coronary lesions or normal coronary arteries $(21 \%$ in women vs. $11 \%$ in men, $p<0.001$ ) [6]. Nonetheless, a widespread invasive strategy implementation is crucial for the improvement in prognosis. In our study it was the strongest independent predictor of decreased mortality.

The most important and still unresolved issue is the persisting gender-related difference in prognosis. Former studies were inconclusive, but in general, unadjusted mortality rates were significantly higher in women. Also, our analysis revealed that unadjusted mortality rates were significantly higher in women. Age-adjusted analyses provided additional data. In both models there were no differences both in the in-hospital and the long-term mortality. Previous observations that mortality in older women is not as high as expected have been verified [3, 16-18]. These results are in contradiction with those from the unadjusted analysis in the general population, but this can be explained by taking into account the influence of the age factor. With each decade of life, the relative risk of death increases, which is in line with the reports by Radovanovic et al. [9] and Bucholz et al. [19]. Poor prognosis in elderly patients results from many factors, i.e. advanced coronary artery disease, more frequent comorbidities, atypical or late presentation of symptoms, as well as exposure to complications and side effects of treatment [15].

In the subgroup of patients treated with $\mathrm{PCl}$ the results were similar. After age classification women had at least the same prognosis as men. Surprisingly, the long-term mortality was even lower in women in several age groups. Finally, female gender did not impact the in-hospital mortality but slightly improved the long-term prognosis. This implies the most important rule in the analysis of any gender-related discrepancies in the field of acute coronary syndromes: the age-adjusted approach. This also provides the novel finding that the prognosis in females with NSTEMI is at least the same as in men when managed according to the guidelines [19-22].

There were several limitations of our study. The PL-ACS Registry is a voluntary, observational study, and not all hospitals treating NSTEMI in Poland participated in data collection. What is more, the absence of some important measures, such as troponin assays, and the retrospective nature of our analysis are also potential weaknesses. On the other hand, PL-ACS is one of the largest contemporary national registries of patients with acute coronary syndromes and provides exceptional data in that issue. Our findings are in accordance with the latest observations in other countries.
In conclusion, our study provides additional data contributing to the ongoing debate on gender-related differences in the management and prognosis in NSTEMI patients. We clearly demonstrated that women, when treated with appropriate access to interventional treatment and modern pharmacotherapy, still have worse short- and long-term prognosis, but this is ascribed mostly to their advanced age. After adjustment for age, those discrepancies no longer exist. Moreover, in some age groups the interventional treatment may be more beneficial in women.

\section{Conflict of interest}

The authors declare no conflict of interest.

\section{References}

1. Poloński L, Gasior M, Gierlotka M, et al.; Polish Registry of Acute Coronary Syndromes (PL-ACS). Characteristics, treatments and outcomes of patients with acute coronary syndromes in Poland. Kardiol Pol 2007; 65: 861-72.

2. Gierlotka M, Gąsior M, Wilczek K, et al. Temporal trends in the treatment and outcomes of patients with non-STsegment elevation myocardial infarction in Poland from 2004-2010 (from the Polish Registry of Acute Coronary Syndromes). Am J Cardiol 2012; 109: 779-86.

3. Hamm CW, Bassand JP, Agewall S, et al. ESC Guidelines for the management of acute coronary syndromes in patients presenting without persistent ST-segment elevation: the Task Force for the management of acute coronary syndromes (ACS) in patients presenting without persistent ST-segment elevation of the European Society of Cardiology (ESC). Eur Heart J 2011; 32: 2999-3054.

4. Donataccio MP, Puymirat E, Parapid B, et al. In-hospital outcomes and long-term mortality according to sex and management strategy in acute myocardial infarction. Insights from the French ST-elevation and non-ST-elevation Myocardial Infarction (FAST-MI) 2005 Registry. Int J Cardiol 2015; 201: 265-70.

5. Simon T, Puymirat E, Lucke V, et al. Acute myocardial infarction in women. Initial characteristics, management and early outcome. The FAST-MI registry. Ann Cardiol Angeiol 2013; 62: 221-6.

6. Isorni MA, Blanchard D, Teixeira N, et al. Impact of gender on use of revascularization in acute coronary syndromes: the national observational study of diagnostic and interventional cardiac catheterization (ONACI). Catheter Cardiovasc Interv 2015; 86: 58-65.

7. Blomkalns AL, Chen AY, Hochman JS, et al. Gender disparities in the diagnosis and treatment of non-ST-segment elevation acute coronary syndromes: large-scale observations from the CRUSADE. J Am Coll Cardiol 2005; 45: 832-7.

8. Bugiardini R, Yan AT, Yan RT, et al. Factors influencing underutilization of evidence-based therapies in women. Eur Heart J 2011; 32: 1337-44.

9. Radovanovic D, Erne P, Urban P, et al. Gender differences in management and outcomes in patients with acute coronary syndromes: results on 20,290 patients from the AMIS Plus Registry. Heart 2007; 93: 1369-75.

10. Kołodziej M, Kurzawski J, Janion-Sadowska A, et al. Mortality of women with ST-segment elevation myocar- 
dial infarction and cardiogenic shock - results from the PL-ACS registry. Medical Studies 2016; 32: 157-63.

11. Poon S, Goodman SG, Yan RT, et al. Bridging the gender gap: Insights from a contemporary analysis of sex-related differences in the treatment and outcomes of patients with acute coronary syndromes. Am Heart J 2012; 163: 66-73.

12. Schmidt M, Jacobsen JB, Lash TL, Bøtker HE, Sørensen HT. 25 year trends in first time hospitalisation for acute myocardial infarction, subsequent short and long term mortality, and the prognostic impact of sex and comorbidity: a Danish nationwide cohort study. BMJ 2012; 344: e356.

13. Malkin CJ, Prakash R, Chew DP. The impact of increased age on outcome from a strategy of early invasive management and revascularisation in patients with acute coronary syndromes: retrospective analysis study from the ACACIA registry. BMJ Open 2012; 2: e000540.

14. Jortveit J, Govatsmark RE, Langørgen J, et al. Gender differences in the assessment and treatment of myocardial infarction. Tidsskr Nor Laegeforen 2016; 136: 1215-22.

15. Sielski J, Janion-Sadowska A, Sadowski M, et al. Differences in presentation, treatment, and prognosis in elderly patients with non-ST-segment elevation myocardial infarction. Pol Arch Med Wewn 2012; 122: 253-61.

16. Redfors $\mathrm{B}$, Angerås $\mathrm{O}$, Råmunddal $\mathrm{T}$, et al. Trends in gender differences in cardiac care and outcome after acute myocardial infarction in western Sweden: a report from the Swedish Web System for Enhancement of Evidence-Based Care in Heart Disease Evaluated According to Recommended Therapies (SWEDEHEART). J Am Heart Assoc 2015; 4: pii: e001995.

17. Alfredsson J, Lindbäck J, Wallentin L, Swahn E. Similar outcome with an invasive strategy in men and women with non-ST-elevation acute coronary syndromes: from the Swedish Web-System for Enhancement and Development of Evidence-Based Care in Heart Disease Evaluated According to Recommended Therapies (SWEDEHEART). Eur Heart J 2011; 32: 3128-36.

18. Darling CE, Fisher KA, MCManus DD, et al. Survival after hospital discharge for ST-segment elevation and nonST-segment elevation acute myocardial infarction: a population-based study. Clin Epidemiol 2013; 5: 229-36.

19. Bucholz EM, Butala NM, Rathore SS, Dreyer RP, Lansky AJ, Krumholz HM. Sex differences in long-term mortality after myocardial infarction: a systematic review. Circulation 2014; 130: 757-67.

20. Heer T, Gitt AK, Juenger $C$, et al. Gender differences in acute non-ST-segment elevation myocardial infarction. Heart 2007; 93: 1327-8.

21. Bradshaw PJ, Thompson PL. Sex in the CCU: women with non-ST-segment elevation acute coronary syndrome may do no worse despite less intervention. Am J Cardiol 2006; 98: 160-6.

22. Alfredsson J, Stenestrand U, Wallentin L, Swahn E. Gender differences in management and outcome in non-ST-elevation acute coronary syndrome. Heart 2007, 93: 1357-62. 